\title{
A NEW APPROACH FOR INTERNET ADVERTISEMENTS
}

\author{
Angel Palacios \\ angel.palacios.orueta@gmail.com
}

\begin{abstract}
Traditional video ads in TV are not well suited for Internet sites. If the user feels a site is forcing $\mathrm{him} / \mathrm{her}$ to watch long video ads, will stop visiting that site. Therefore, the current approach is to allow the user to skip the ad after a few seconds, despite this means that the ads will have little impact. This paper presents a new approach that engages the user with the brand, while at the same time keeping the user in the website. The approach works by asking the user a question relating to the ad, and if the user responds correctly, the ad is immediately removed. This approach presents benefits both for users and advertisers. The benefit for the user is that (s)he can skip the ad immediately. The benefit for the advertiser is that by putting mental effort on the brand, the brand has more impact on the user.
\end{abstract}

\section{INTRODUCTION}

Traditional TV commercials are too long for the Internet. So, when the user is expecting to get some actual content, and (s)he finds a video commercial that might be long, (s)he quickly hops to a different web page. Therefore, web sites have the option to use this approach, but they risk creating an aggressive reputation in the users' mind. After a few attempts, the user might never come back.

Advertisers have found a way to retain the user, which is to allow him/her to skip to the actual content after a few seconds. When the video commercial starts, it also shows a sign indicating a message such as "you can skip this ad in 5 seconds". As time passes by, the number of seconds is reduced. At the end, if the user does not want to watch the commercial, (s)he can click a button to close the commercial and move on to the actual content.

Figure 1 shows this current standard approach in Internet videos. The arrow with the "(1)" label indicates the message that informs the user that (s)he can skip the video in a few seconds. 


\section{Versy Travel}

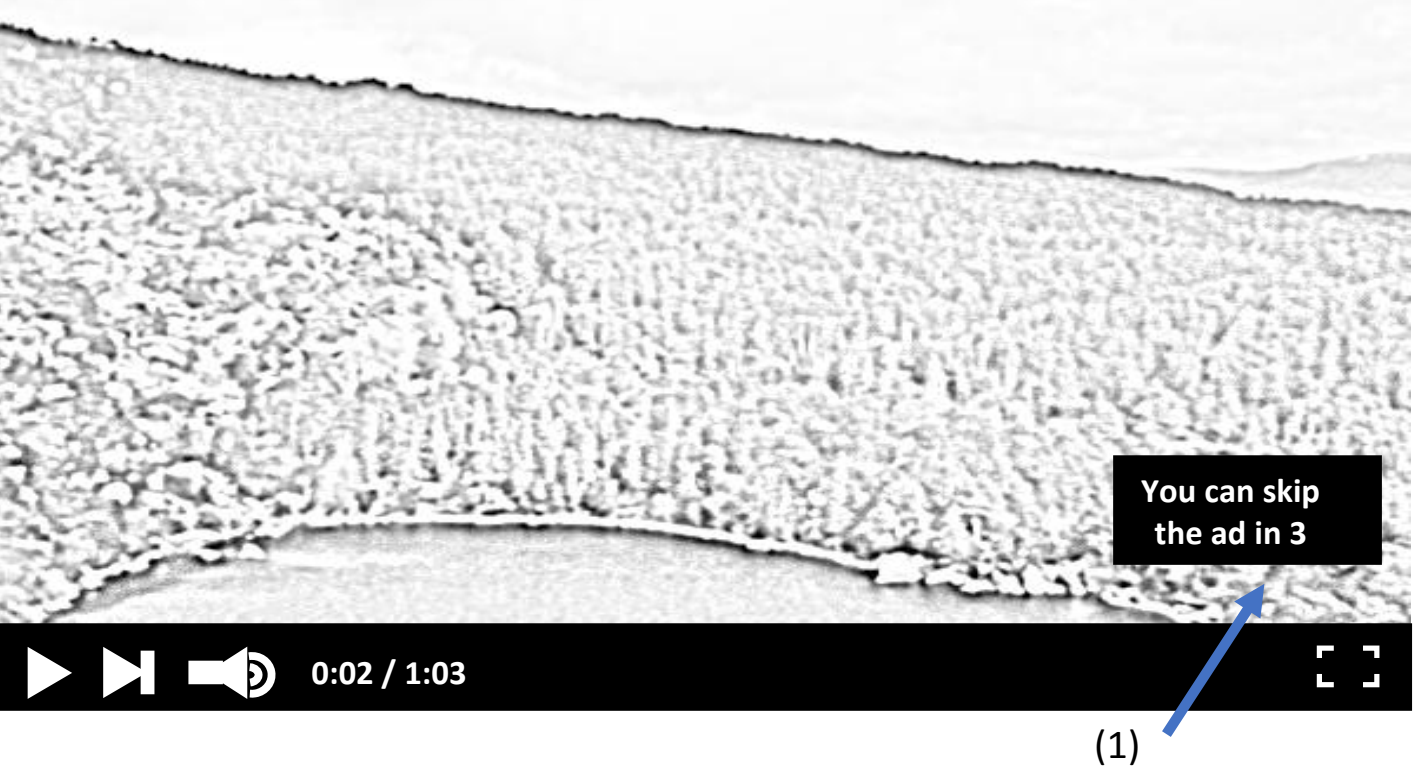

Figure 1. Standard approach in Internet video commercials

Generally, advertisers show the brand name during the initial seconds in some part of the commercial, or the commercial itself utters it. This way, at the minimum, advertisers hope to pass part of the message to the user during those few seconds. And if the commercial is attractive enough, get the user to watch it in its entirety. Users do not reject web sites using this approach because they feel they are being respected to some extent.

The problem for advertisers is that this approach still does not have a big impact on the user, because the user will often ignore the message they see during those initial seconds. This effect of user ignoring Internet ads is known as "banner blindness" (Benway, 1998; Benway \& Lane, 1998; Hervet, Guérard, Tremblay, \& Chtourou, 2011). It is reasonable to expect it to happen as well regarding the ad texts shown at the beginning of internet video ads.

\section{THE NEW APPROACH}

The new approach seeks to engage the user with the brand while at the same time respecting his or her time. Figure 2 shows a possible way to implement this approach. The "Skip Ad" sign has been moved to the left. On the right, a new sign has been included, indicated with the label "(2)". This new sign gives the user the possibility to answer an ad related question. It shows a brand name (PG) and an ad title ("P\&G Gracias, Mamá"). The question is whether this brand name and ad title corresponds to the ad being shown. The user has two possible choices: click on "yes" or "no". 


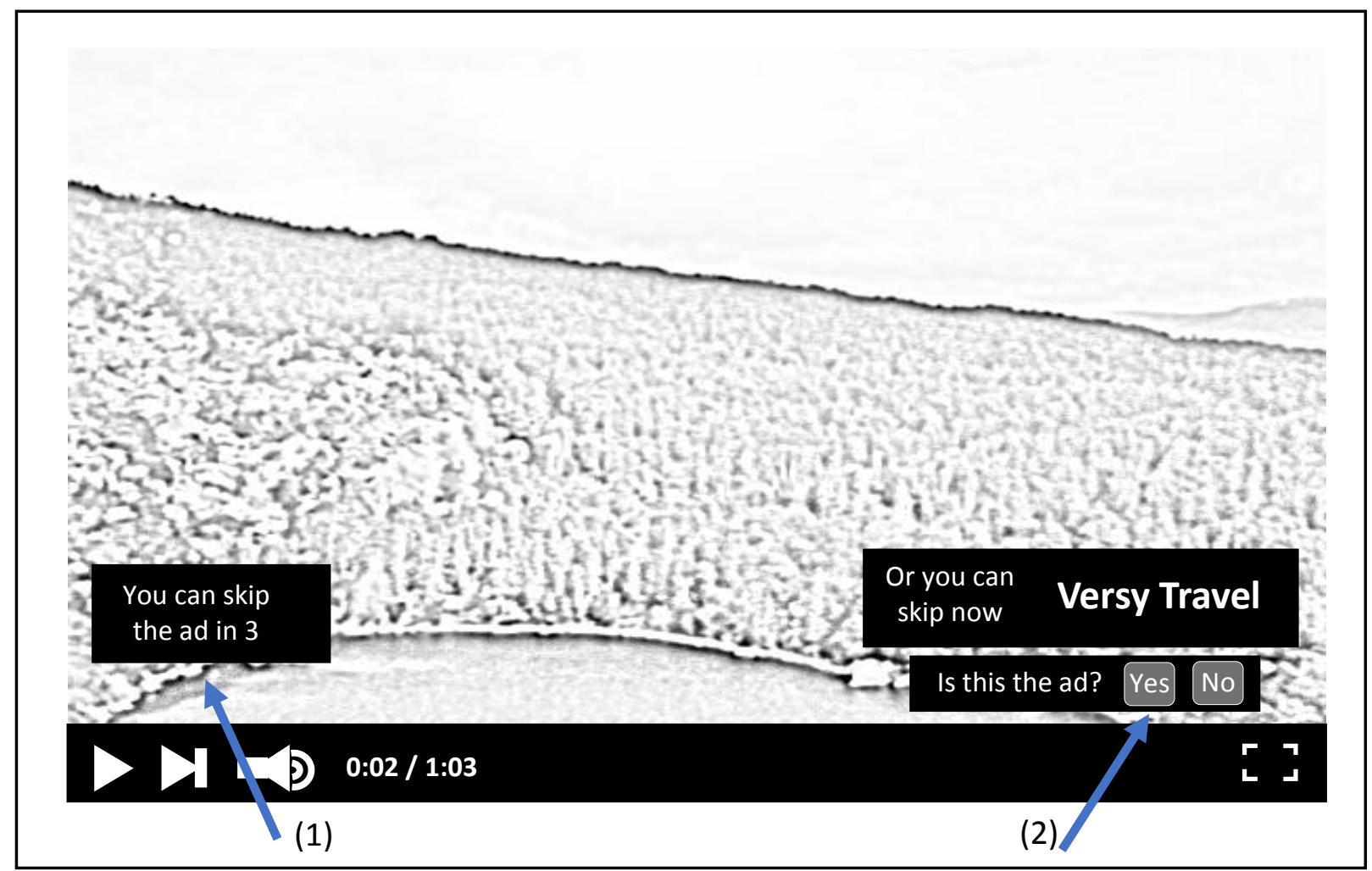

Figure 2. New approach in Internet video commercials

If the user's response is correct, the ad closes and the user can immediately obtain the content that he or she is interested in. This is suggested by the message reading "Or you can skip now", which is shown on the right bottom corner.

\section{BENEFITS OF THE NEW APPROACH}

With the approach illustrated in Figure 2, the user still have the benefits of the standard approach, as shown by the area "(1)", as (s)he can still wait a few seconds and skip the ad.

And at the same time, this approach provides two important benefits, one for the user and one for the advertiser. The benefit for the user is that (s)he can immediately use the sign on the right bottom part to respond to the question posed. If the answer is correct, (s)he can remove the video immediately, rather than after a few seconds.

The benefit for the advertiser is that while the user is reading and replying to the question, (s)he is engaging with the brand. Rather than passively watching or ignoring the add, (s)he will read the text shown in (2) and will pay attention to the first images of the ad. This will make both these first images and the text to be remember better, as research in cognitive psychology has shown ( for a general review, see Brown, Roediger, \& McDaniel, 2014). Memory retains information better when the person puts effort and attention.

Furthermore, (Jacoby, 1978) performed an experiment that is structurally very close to the current situation. They created a list of word pairs, gave them to different subjects, and asked the subjects to read out the second word. For example, she would be asked to read out "trouser" in the pair "leg-trouser". In some cases the second word was shown incomplete, such as in "foot$s_{-} e^{\prime \prime}$, and the subject was asked to construct the word before reading it out. After that, a 
memory test was given to the users, whereby the user might be given one of the first words in the pairs, such as "leg", and asked to provide the word that was associated to it.

Subjects showed a much higher retention of words that they had to construct (i.e. "shoe") than of words they just read (i.e. "trouser"). It is expected that this experiment would work in the same way in the case of Internet video ads, considering the formal similarities between both of them. The beginning of the commercial is the first word ("foot") and the brand is the second word ("shoe"). Therefore, guessing the brand after seeing the commercial should enhance memory for it.

From the commercial point of view, in some instances, the text in " 2$)^{\prime \prime}$ will not correspond to the ad. Otherwise, the user would always click on "yes". When the text does not correspond to the ad, the fact that the user is reading that text will only benefit the advertiser if the text corresponds to another product, service or entity in which the advertiser has interest. This might be, for example, another product sold by the same company, or another product sold by a different company with whom the company advertising now has some liaison. For example, it might be another company with whom the company has an agreement in order to use each other products as alternatives for the questions posed in "(2)". In this case, if company A and company $B$ has such agreement, the ads shown by company $A$ will sometimes benefit company $B$, and the ads shown by company $B$ will sometimes benefit company $A$.

\section{IMPLEMENTATION ALTERNATIVES}

\section{Multi entity question}

Figure 2 only shows just one possible way to implement this new approach. There are countless other ways. For example, Figure 3a shows a different type of implementation. In this case, there are several alternatives where the user can click (Scent Spas, Versky Travels, Hegin Hotels). Each one of these entities correspond to a different brand, product, service or entity in general that can be advertised. When the user clicks on one of them, the system interprets that the user is indicating that the entity been clicked is the one that is the subject of the commercial. If that is true, the commercial disappears and the user can obtain the real content.

The user has many different ways to choose the desired alternative. For example, in a situation such as shown in Figure $3 \mathrm{~b}$, the user would enter the letter that corresponds to the desired alternative. 


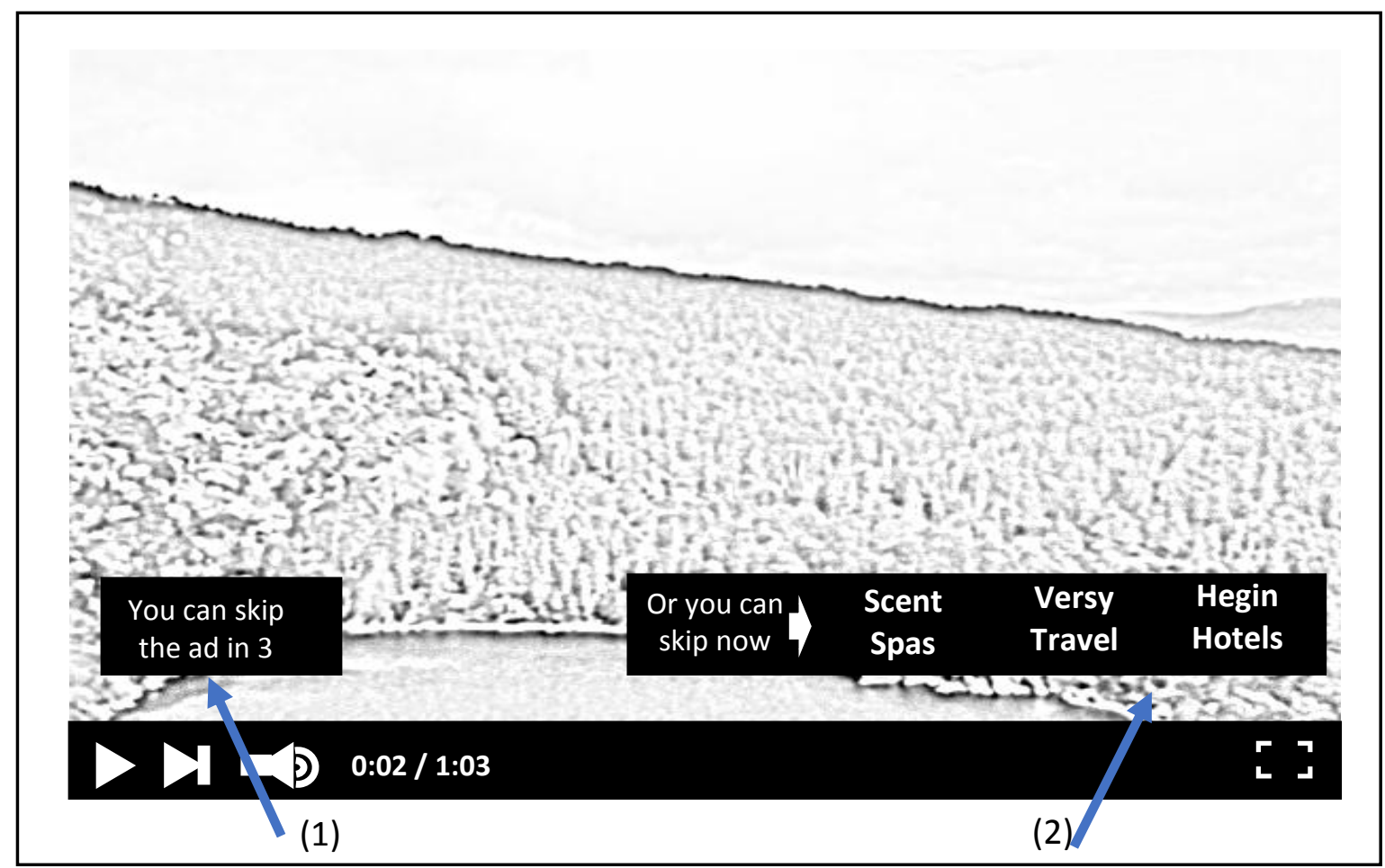

Figure 3a. Alternative version of new approach in Internet video commercials

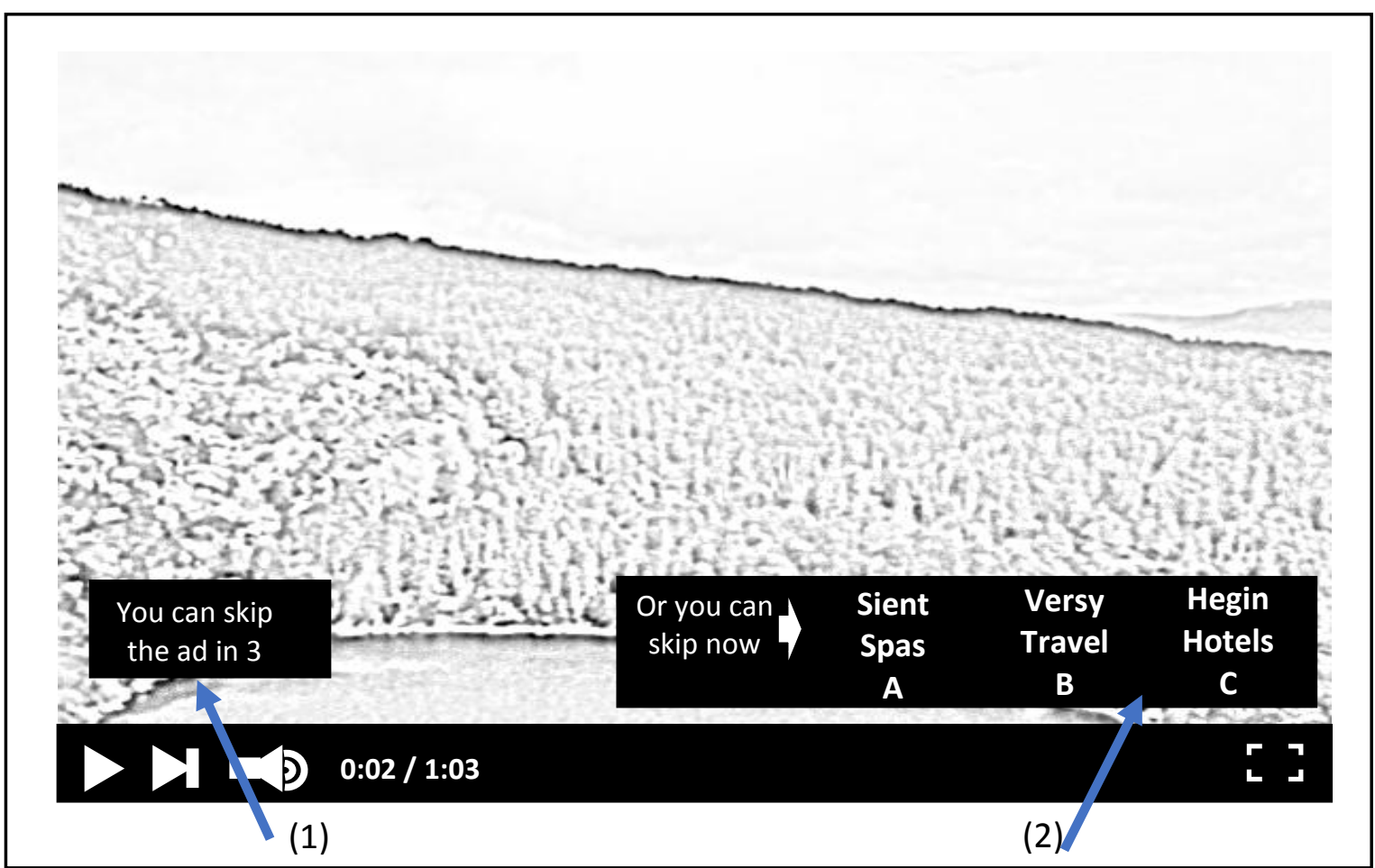

Figure 3b. Alternative version of new approach in Internet video commercials 


\section{Generic question}

Figure 4 illustrates another way to implement this new approach. In this case, the question posed by "(2)" asks a generic question about the entity being advertised. In this case, the question is "Is it a travel agency?" If the entity is, a "yes" answer would provide the user the content (s)he is really interested in.

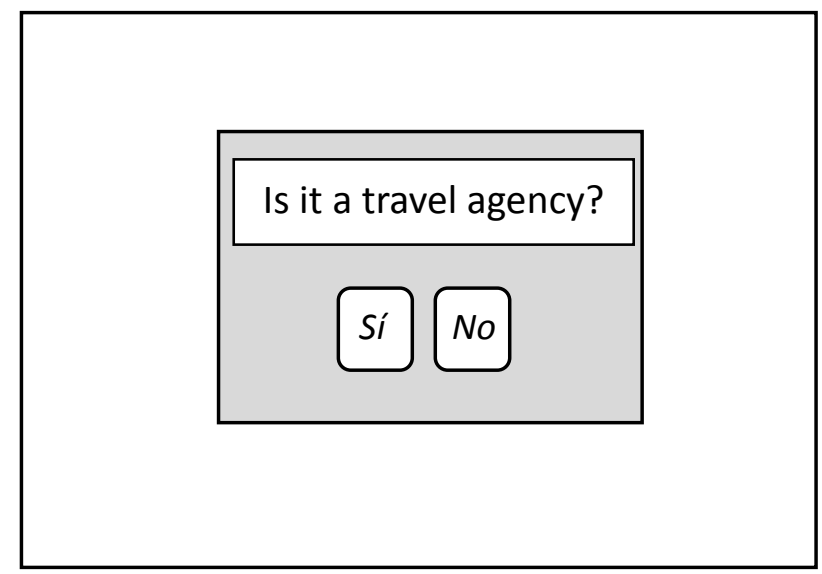

Figure 4. Alternative version of new approach in Internet video commercials

\section{TV implementation}

This current approach can also be used in traditional TV, instead of traditional commercials, as illustrated in Figure 5. For this implementation, the TV would need an Internet connection, which they usually have nowadays.

In the normal programming state (a), the TV is performing in the traditional way, and is receiving the regular TV signal, for example from the antenna. However, it could be getting it from cable or via any other means, which could actually be the Internet.

In that state, when a commercial break happens the TV would switch to state (b) and connect to the Internet, to a server hosting different commercials, and would show a commercial. In order for this to happen, at this point the TV screen will show the videos retrieved from the Internet, rather than the normal TV programming. Also, the TV screen will show a question for the user to answer, related to the entity being advertised.

The user might reply using the remote control, for example, to point to a given control and press enter to select it. If the user's response is correct, the commercial disappears and a new commercial appears.

When the time allocated to commercials in normal programming is over, the TV would switch to state (c). If the user has managed to answer correctly one or more of the questions, the commercials that have been viewed by the user will be the same as the commercials being shown in normal programming. But when the last commercial is over, there will be some time left. In order to compensate the user for that, the TV will warn the user when the regular TV programming is about to start again. For that, the TV will generate a beep, for example. In the meantime, during that some time left, the user might choose to use the TV on Internet mode, to switch to normal programming, or to do something else away from the TV. 


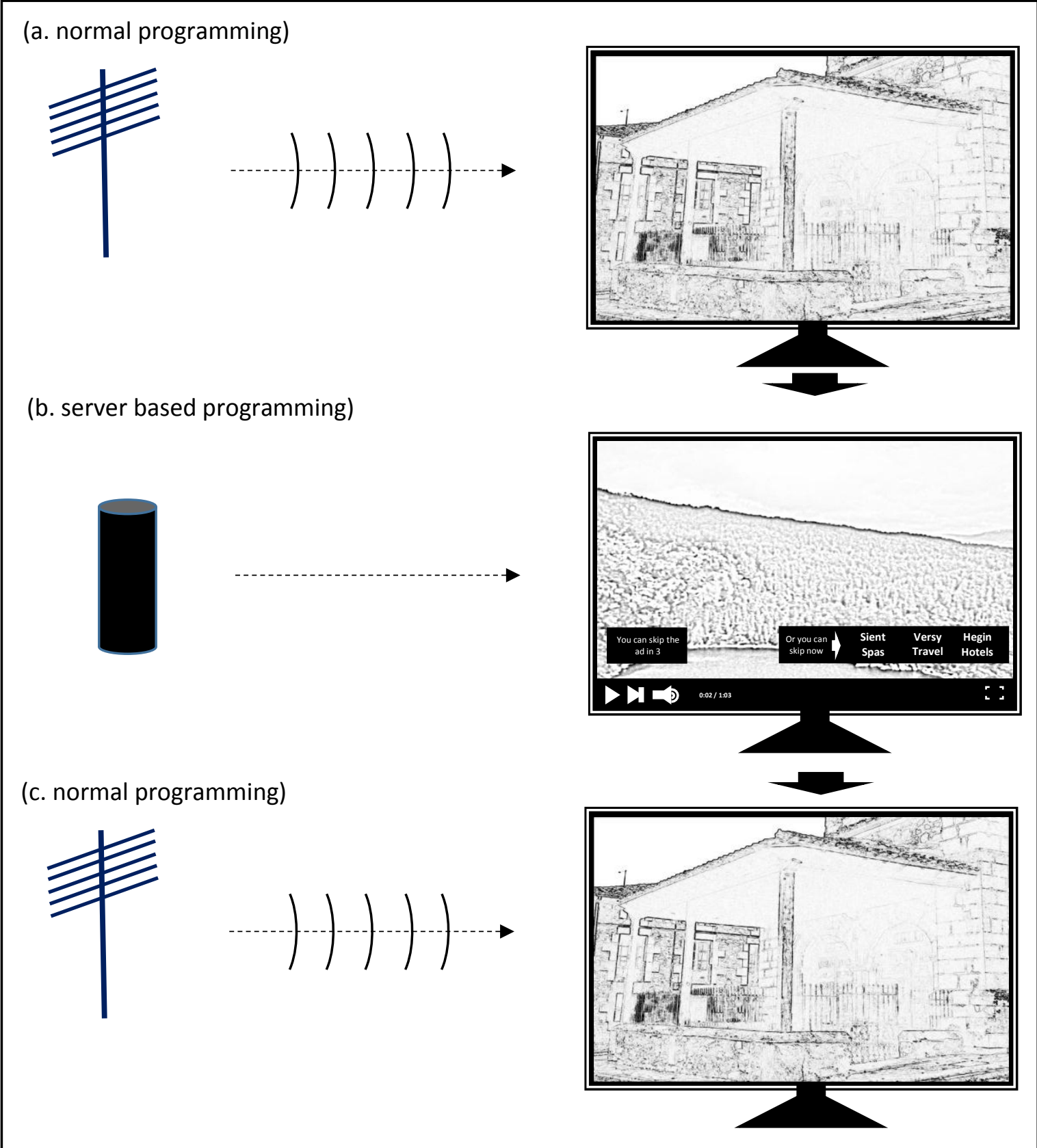

Figure 5. Traditional TV version of new approach in Internet video commercials

\section{$\underline{\text { Static ad implementation }}$}

The same approach can be applied to the static ads that appear on a webpage when the user is opening it. Generally, these are ads that cover a significant part of the webpage, so hiding a significant part of the content that the user is potentially interested in. In this ads, there generally appears a control that when the user clicks, which is control (1) in Figure 6a, makes the ads disappear. This control may show immediately or after a while.

As in the case of video ads, the result is that the user clicks on it without paying attention to the entity being advertised. In the new approach, two controls similar to "(1)" and "(2)" would be 
shown to allow the user to remove the ad after a short time (control 1.) or immediately if the user responds correctly to the question (control 2.). In static ads, the brand must be shown on the ad, so the user will always have the possibility to be right if (s)he pays attention. The benefit for the advertiser is that the user would pay attention. The benefit for the user is that (s)he would close the ad immediately.

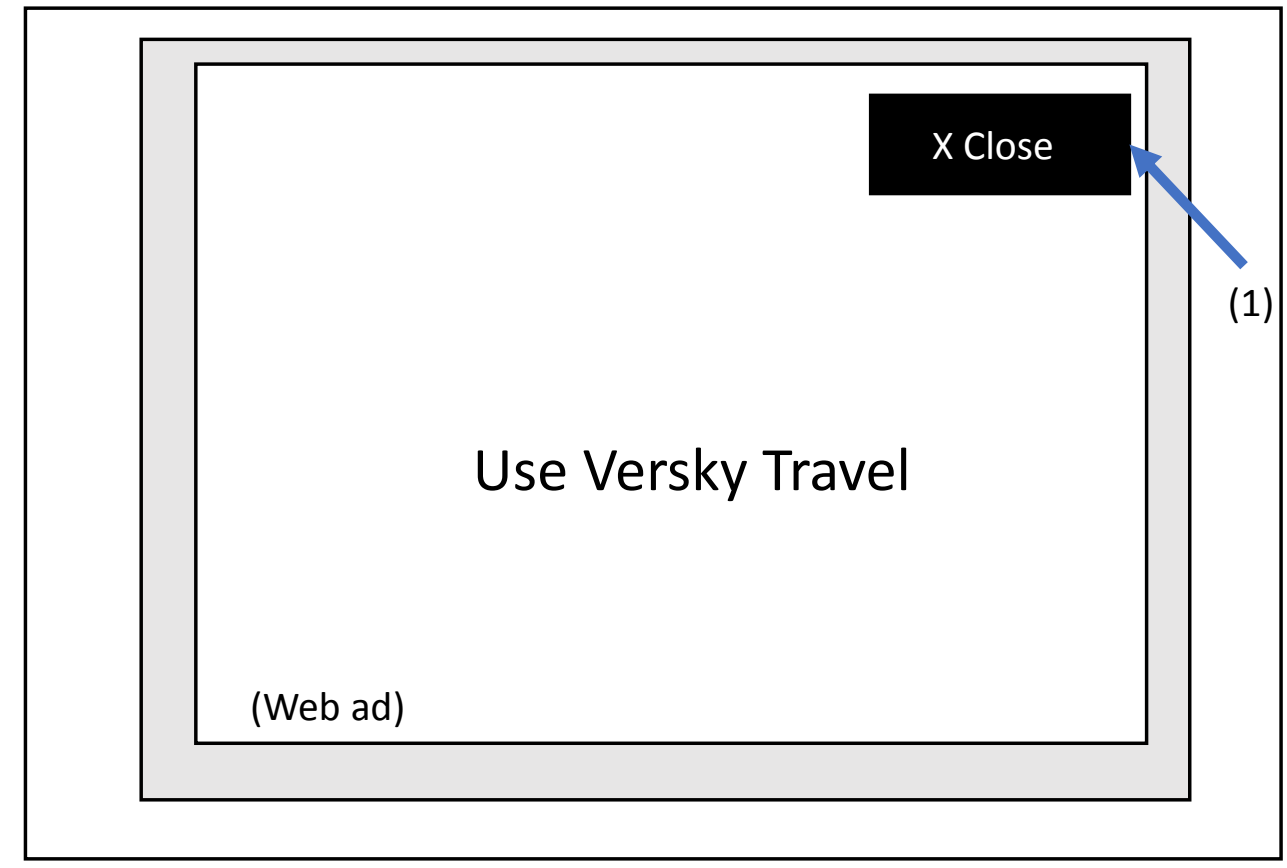

Figure 6a. Current practice in static ads

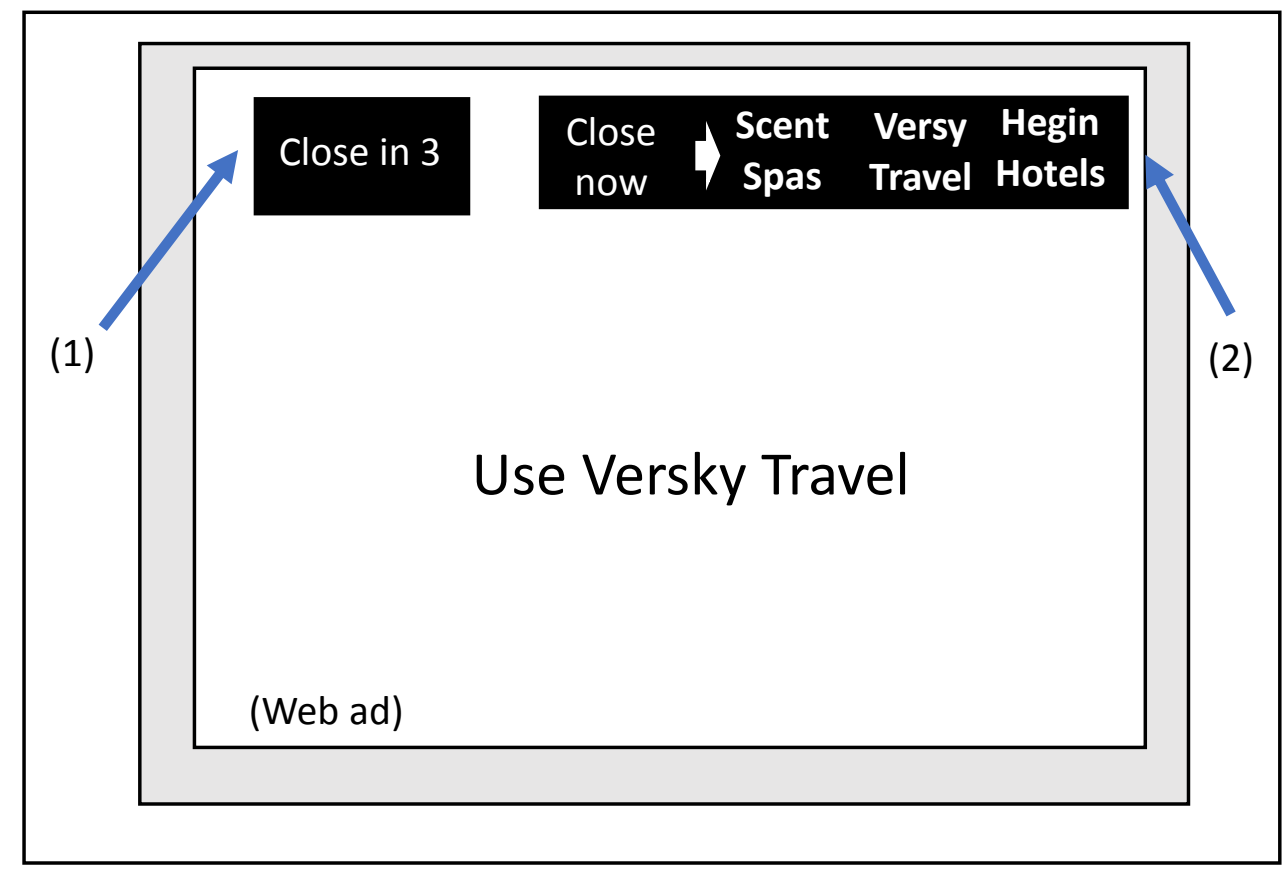

Figure 6b. New approach for static ads

\section{CONCLUSIONS}

The traditional approach to video commercials is not well applicable to the Internet. The Internet provides a great amount of content, so if a user feels that a website is making him/her spend 
long times watching commercials, (s)he will not enter it. An approach was developed for Internet that has become the current standard practice, which consists in the user having the option to remove the ad after a few seconds. Still, this practice does not benefit the advertiser very much, and still keeps the user watching a few seconds of a commercial that (s)he might already know.

This paper presents a new approach for Internet commercials. This approach consists on allowing the user to remove the commercial if (s)he responds correctly to a question related to the entity being advertised. The benefit of this approach for the advertiser is that it engages the user with the brand. The benefit for the user is that, at the same time, it does not make the user watch a commercial that they might already know.

\section{REFERENCES}

Benway, J. P. (1998). Banner blindness: The irony of attention grabbing on the World Wide Web. In Proceedings of the Human Factors and Ergonomics Society Annual Meeting (Vol. 42, pp. 463-467). inproceedings.

Benway, J. P., \& Lane, D. M. (1998). Banner blindness: Web searchers often miss "obvious" links. Itg Newsletter, 1(3), 1-22. article.

Brown, P. C., Roediger, H. L., \& McDaniel, M. A. (2014). Make it stick. book, Harvard University Press.

Hervet, G., Guérard, K., Tremblay, S., \& Chtourou, M. S. (2011). Is banner blindness genuine? Eye tracking internet text advertising. Applied Cognitive Psychology, 25(5), 708-716. article. http://doi.org/10.1002/acp.1742

Jacoby, L. L. (1978). On interpreting the effects of repetition: Solving a problem versus remembering a solution. Journal of Verbal Learning and Verbal Behavior, 17(6), 649-667. article. 